Document downloaded from:

http://hdl.handle.net/10251/142042

This paper must be cited as:

Deng, X.; Albero-Sancho, J.; Xu, L.; García Gómez, H.; Li, Z. (07-2). Construction of a Stable Ru-Re Hybrid System Based on Multifunctional MOF-253 for Efficient Photocatalytic CO2 Reduction. Inorganic Chemistry. 57(14):8276-8286.

https://doi.org/10.1021/acs.inorgchem.8b00896

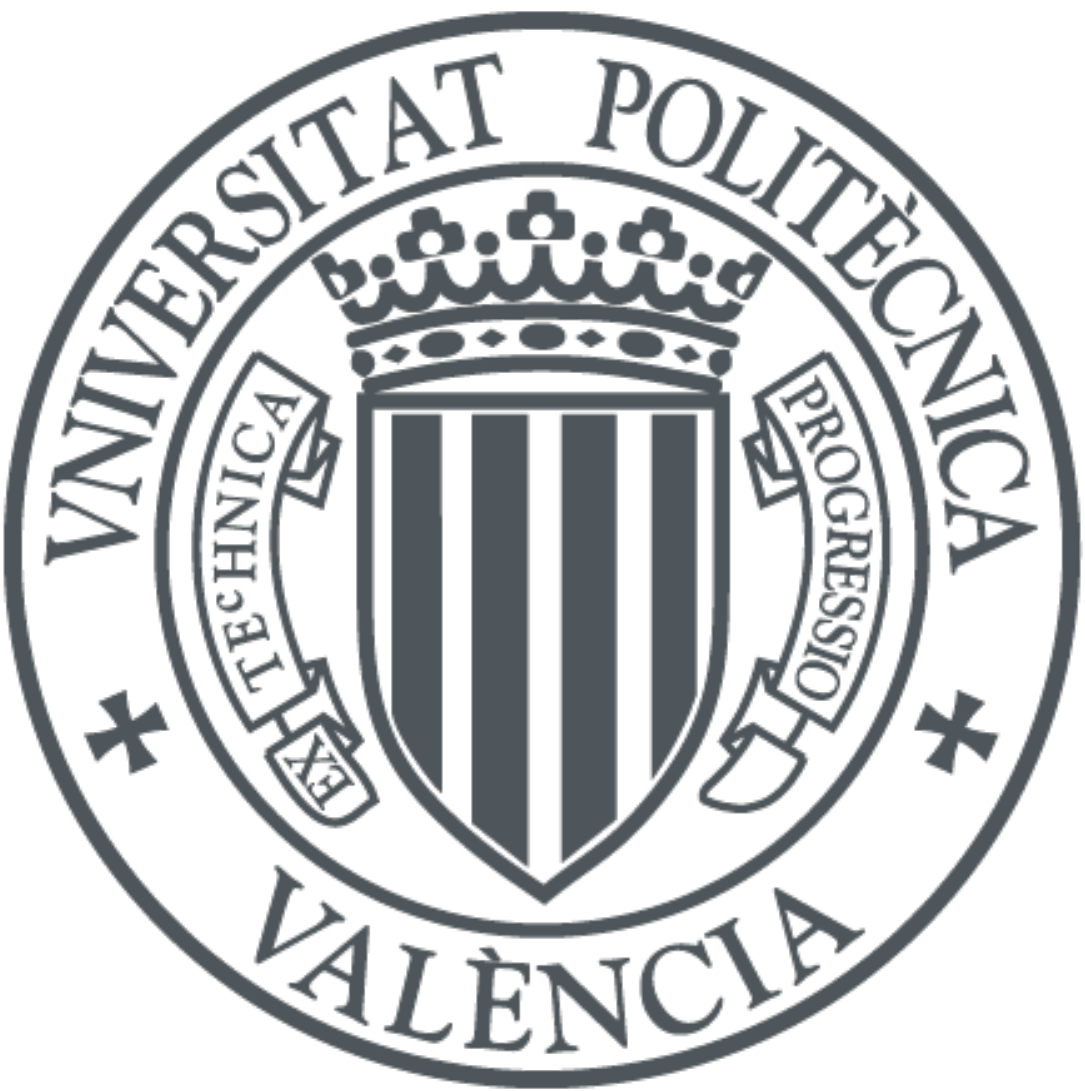

The final publication is available at

https://doi.org/10.1021/acs.inorgchem.8b00896

Copyright American Chemical Society

Additional Information 


\title{
Construction of a Stable Ru-Re Hybrid System Based on Multifunctional MOF-253 for Efficient Photocatalytic $\mathrm{CO}_{2}$ Reduction
}

\author{
Xiaoyu Deng, Lizhi Xu, Zhaohui Li* \\ Research Institute of Photocatalysis, State Key Laboratory of Photocatalysis on \\ Energy and Environment, College of Chemistry, Fuzhou University, Fuzhou 350116, \\ People's Republic of China
}

* Author to whom all correspondences should be addressed.

E-mail: zhaohuili1969@yahoo.com (Z. Li), Tel (Fax): 86-591-22865855. 


\begin{abstract}
Using the open $\mathrm{N}, \quad \mathrm{N}$ '-chelating sites of $\mathrm{MOF}-253$ ( $\mathrm{Al}(\mathrm{OH})(\mathrm{dcbpy}))$ (dcbpy=2,2'-bipyridine-5,5'-dicarboxylic acid)to coordinate with $\operatorname{Re}(\mathrm{I})$, a surface supported Re complex MOF-253- $\mathrm{Re}(\mathrm{CO})_{3} \mathrm{Cl}$ active for photocatalytic $\mathrm{CO}_{2}$ reduction was obtained. Unlike the homogeneous bipyridine containing Re complexes which produced $\mathrm{CO}$ during photocatalytic $\mathrm{CO}_{2}$ reduction, the as-obtained MOF-253- $\mathrm{Re}(\mathrm{CO})_{3} \mathrm{Cl}$ produced formate as the main $\mathrm{CO}_{2}$ reduction product. In addition, the surface supported $\mathrm{MOF}-253-\mathrm{Re}(\mathrm{CO})_{3} \mathrm{Cl}$ showed superior photocatalytic performance than its homogeneous counterpart, in which the usual formation of the bimolecular Re intermediate leading to the deactivation of the homogeneous $\mathrm{Re}$ complex was significantly inhibited in MOF supported Re complex. To enhance the light absorption of $\mathrm{MOF}-253-\mathrm{Re}(\mathrm{CO})_{3} \mathrm{Cl}$, a surface supported $\mathrm{Ru}$ sensitizer was simultaneously constructed in it. Via an efficient charge transfer from Ru sensitizer to Re catalytic center, which resembles the construction of Ru-Re supramolecular structure using covalent bonds, the $\mathrm{Ru}$ sensitizedMOF-253- $\mathrm{Re}(\mathrm{CO})_{3} \mathrm{Cl}$ showed superior photocatalytic $\mathrm{CO}_{2}$ reduction under visible light. This study demonstrates the possibility of using MOF with open coordination sites as a multifunctional platform for the construction of stable hybrid systems for artificial photosynthesis.
\end{abstract}




\section{Introduction}

$\mathrm{CO}_{2}$ is a greenhouse gas and the ever increasing combustion of the fossil fuel leads to an excessive emission of $\mathrm{CO}_{2}$ into the atmosphere which results in global warming. [1-5] Although the capture and sequestration of $\mathrm{CO}_{2}$ from post-combustion effluents is an accepted working approach, the use of $\mathrm{CO}_{2}$ as a $\mathrm{C} 1$ building block to produce high-value chemicals via catalytic transformations would be more desirable, especially when such a transformation can be realized by utilization of solar light. However, $\mathrm{CO}_{2}$ has exceptional thermodynamic stability and the direct one-electron reduction of $\mathrm{CO}_{2}$ to the radical anion $\mathrm{CO}_{2}{ }^{-}$is energetically demanding $(-1.97 \mathrm{~V}$ vs NHE). Although multiple electron reduction products like $\mathrm{CO}, \mathrm{HCOOH}, \mathrm{CH}_{3} \mathrm{OH}$ and $\mathrm{CH}_{4}$ can be produced at significantly less negative potentials, their generations are kinetically unfavorable and metal complexes with redox active metal centers and inter-changeable ligands are usually required to realize such multi-electron redox reactions. [6-11] $\mathrm{Re}^{\mathrm{I}}$ diimine complexes $\left[\mathrm{Re}\left(\mathrm{N}, \mathrm{N}^{\prime}\right)(\mathrm{CO})_{3} \mathrm{X}\right]\left(\mathrm{X}=\mathrm{Me}, \mathrm{Cl}^{-}\right.$, etc $)$have been recognized to be efficient catalysts for $\mathrm{CO}_{2}$ reduction to produce $\mathrm{CO}$ or $\mathrm{HCOO}^{-}$ via two-electron proton coupled reduction pathways. [12-18] However, these Re diimine complexes showed poor absorption in visible light region. To be applied in photocatalytic $\mathrm{CO}_{2}$ reduction under visible light, bimetallic $\mathrm{M}-\mathrm{Re}(\mathrm{M}=\mathrm{Ru}, \mathrm{Ir}, \mathrm{Os})$ supramolecular structures by attaching Re complexes to photosensitizers via covalent bonds should be constructed. [19-24] However, the preparations of such supramolecules are usually challenging and tedious. In addition, these supramolecules also suffer from all the disadvantages of being homogeneous catalysts, like the difficultly in separation from the reaction systems for recycling.

The use of porous materials as supports to heterogenize the homogeneous catalysts is a generally adopted strategy. [25-29] Metal-organic frameworks (MOFs), a class of porous materials constructed from the metal/metal clusters and poly-dentated organic ligands, have been targeted as attractive supports for the molecular catalysts over the past years, due to their well-defined and highly tunable porous structures. [29-45] MOFs can offer or be endowed with well defined isolated sites for anchoring of catalytic active species. Actually, MOFs-supported molecular catalysts for a variety of organic transformations have been obtained. [46-49] Especially, a direct construction of metal complexes using MOFs themselves as solid ligand is an ideal 
strategy to develop supported molecular catalysts without losing their performance. [25, 50, 51] With opening $\mathrm{N}, \mathrm{N}^{\prime}$-chelating sites in its structure, MOF-253 $(\mathrm{Al}(\mathrm{OH})(\mathrm{dcbpy}))\left(\mathrm{dcbpy}=2,2^{\prime}\right.$-bipyridine-5,5'-dicarboxylic acid) is an ideal solid ligand for construction of surface supported metal complex featuring bpy ligands. Actually several previous studies have already been conducted on the functionalizations of MOF-253 with $\mathrm{Ru}, \mathrm{Pt}, \mathrm{Ln}(\mathrm{Ln}=\mathrm{Eu}, \mathrm{Tb}, \mathrm{Sm})$ containing complexes using its open N, N'-chelating sites. [52-55]

Herein, we reported the use of open N, N'-chelating sites in MOF-253 to construct supported active $\mathrm{Re}$ carbonyl complex MOF-253- $\mathrm{Re}(\mathrm{CO})_{3} \mathrm{Cl}$ for photocatalytic $\mathrm{CO}_{2}$ reduction under visible light. Unlike the homogeneous bipyridine containing Re complexes which produced $\mathrm{CO}$ during photocatalytic $\mathrm{CO}_{2}$ reduction, the as-obtained $\mathrm{MOF}-253-\mathrm{Re}(\mathrm{CO})_{3} \mathrm{Cl}$ produced formate as the main $\mathrm{CO}_{2}$ reduction product. The as-obtained MOF-253- $\mathrm{Re}(\mathrm{CO})_{3} \mathrm{Cl}$ is more stable than its homogeneous counterpart $\mathrm{Re}(\mathrm{dcbpy})(\mathrm{CO})_{3} \mathrm{Cl}$ since the usual formation of the bimolecular $\mathrm{Re}$ intermediate leading to the deactivation of the homogeneous $\mathrm{Re}$ complex was significantly inhibited in MOF supported Re complex ascribed to the spatially isolated Re moieties in MOF-253. [56-57] To enhance the light absorption capability of MOF-253- $\mathrm{Re}(\mathrm{CO})_{3} \mathrm{Cl}$, a surface supported $\mathrm{Ru}$ sensitizer was simultaneously constructed in MOF-253-Re(CO) ${ }_{3} \mathrm{Cl}$. Via an efficient charge transfer from $\mathrm{Ru}$ sensitizer to $\mathrm{Re}$ catalytic center, the $\mathrm{Ru}$ sensitized-MOF-253- $\mathrm{Re}(\mathrm{CO})_{3} \mathrm{Cl}$ show superior performance for photocatalytic $\mathrm{CO}_{2}$ reduction under visible light. The use of MOF-253 as a platform for assembling $\mathrm{Ru}$ photosensitizer and Re catalyst resembles the construction of the light chromophores with catalytic components via covalent bonds to form the supramolecular structures reported previously, but is more facile in synthesis. This study demonstrates the possibility of using MOF with open coordination sites as a multifunctional platform for the construction of stable hybrid systems for artificial photosynthesis.

\section{Experimental}

\section{Preparations}

All the chemicals were obtained commercially and used without further purifications. MOF-253 was synthesized following the previous literature. [52] MOF-253- $\mathrm{Re}(\mathrm{CO})_{3} \mathrm{Cl}$ was synthesized from $\mathrm{MOF}-253$ and $\mathrm{Re}(\mathrm{CO})_{5} \mathrm{Cl}$ under refluxing. Before reaction, MOF-253 was de-solvated under vacuum at $150{ }^{\circ} \mathrm{C}$ overnight. The vacuum-treated MOF-253 (428.7 $\mathrm{mg}, 1.5 \mathrm{mmol})$ and $\operatorname{Re}(\mathrm{CO})_{5} \mathrm{Cl}$ 
(108.5 mg, $0.3 \mathrm{mmol})$ were refluxed in anhydrous toluene $(60 \mathrm{ml})$ for $2 \mathrm{~h}$ in $\mathrm{N}_{2}$ atmosphere. After the reaction, the resultant powder was filtered, washed with $\mathrm{MeOH}$ and dried under vacuum to give the yellow product (147.2 $\mathrm{mg}, 83 \%$ ).

Sensitized-MOF-253- $\mathrm{Re}(\mathrm{CO})_{3} \mathrm{Cl}$ was prepared by reacting $\mathrm{MOF}-253-\mathrm{Re}(\mathrm{CO})_{3} \mathrm{Cl}$ with $\mathrm{Ru}(\mathrm{bpy})_{2} \mathrm{Cl}_{2}$ (bpy=2,2'-bipyridine) in $\mathrm{MeOH}$. $\mathrm{Ru}(\mathrm{bpy})_{2} \mathrm{Cl}_{2}(2.0 \mathrm{mg}, 2.6 \mu \mathrm{mol})$ was dissolved in a minimum amount of $\mathrm{MeOH}$. MOF-253- $\mathrm{Re}(\mathrm{CO})_{3} \mathrm{Cl}(50.0 \mathrm{mg})$ was added to the above solution and the resultant suspension was incubated at room temperature for $12 \mathrm{~h}$. The resultant product was washed with $\mathrm{MeOH}$ for several times and dried at $60{ }^{\circ} \mathrm{C}$ under vacuum to obtain a deep orange powder. For comparison, $\mathrm{Ru}(\mathrm{bpy})_{2} \mathrm{Cl}_{2}$ supported on MOF-253 (MOF-253-Ru) was prepared by reacting $\mathrm{Ru}(\mathrm{bpy})_{2} \mathrm{Cl}_{2}$ with MOF-253.

Homogeneous $\operatorname{Re}(\mathrm{dcbpy})(\mathrm{CO})_{3} \mathrm{Cl}$ was prepared according to the method reported previously with slight modifications. $[18,58] \mathrm{Re}(\mathrm{CO})_{5} \mathrm{C} 1(289 \mathrm{mg}, 0.8 \mathrm{mmol})$ was dissolved in toluene at $60{ }^{\circ} \mathrm{C}$ and dcbpy (195 mg, $\left.0.8 \mathrm{mmol}\right)$ was added to the above solution, causing a color change from pale yellow to deep red. The mixture was stirred and heated at $80{ }^{\circ} \mathrm{C}$ for $2 \mathrm{~h}$. The suspension was filtered and the product was washed with $\mathrm{MeOH}$ and dried under vacuum to obtain the red product.

\section{Characterizations}

X-ray diffraction (XRD) patterns were collected on a Bruker D8 Advance X-ray diffractometer with $\mathrm{Cu} \mathrm{K}_{\alpha}$ radiation. The accelerating voltage and the applied current were $40 \mathrm{KV}$ and $40 \mathrm{~mA}$, respectively. Data were recorded at a scan rate of $0.05^{\circ} 2 \theta \mathrm{s}^{-1}$ in the $2 \theta$ range from $5^{\circ}$ to $40^{\circ}$. The IR spectra were obtained on a Nicolet 670 FT-IR spectrometer. UV-vis diffuse-reflectance spectrometry (UV-vis DRS) were obtained on a UV-visible spectrophotometer (Cary 500 Scan Spectrophotometers, Varian). $\mathrm{BaSO}_{4}$ was used as a reference. $\mathrm{N}_{2}$ adsorption/desorption isotherms was carried out at $77 \mathrm{~K}$ on ASAP2020 apparatus (Micromeritics Instrument Corp., USA). Inductively Coupled Optical Emission Spectrometry (ICP-OES) was performed on an Optima 8000 (PerkinElmer). The sample was digested in a mixture of $\mathrm{HNO}_{3}$ and Milli-Q water. EI-MS were detected with Agilent 5977A spectrometer. NMR spectra were obtained on a 400MHz broker AVANCE III 400 system (400 MHz).

\section{Photocatalytic $\mathrm{CO}_{2}$ reduction}

Photocatalyst (5 mg) was vacuumed and purged with $\mathrm{CO}_{2}$. A mixture of DMF, TEOA and $\mathrm{H}_{2} \mathrm{O}(4 \mathrm{ml})$ in a volume ratio of 5:1:0.2, degassed and saturated with $\mathrm{CO}_{2}$ 
to remove any dissolved $\mathrm{O}_{2}$, was injected into the reaction tube. The reaction was carried out under the irradiation of Xe lamp with a UV-cut filter to remove all irradiations with wavelength lower than $420 \mathrm{~nm}$ and an IR-cut filter to remove those with wavelength longer than $800 \mathrm{~nm}$. After the reaction, the amount of produced $\mathrm{HCOO}^{-}$was determined by ion chromatography (881 Compact IC pro, Metrosep) with Metrosep A supp 5 250/4.0 column. A mixture of $3.2 \mathrm{mM} \mathrm{Na}_{2} \mathrm{CO}_{3}$ and $1.0 \mathrm{mM}$ $\mathrm{NaHCO}_{3}$ was used as the eluent. The gaseous products were analyzed by GC-TCD (Shimadzu GC-2014) with a TDX-01 packed column. ${ }^{13} \mathrm{CO}$ performed by Agilent 7890B-5977A GC-MS.

\section{Results and discussion}

MOF-253 with high quality was synthesized following the previously reported method. To prepare MOF-253- $\operatorname{Re}(\mathrm{CO})_{3} \mathrm{Cl}$, the as-synthesized MOF-253 was de-solvated under dynamic vacuum and then refluxed in anhydrous toluene solution containing $\operatorname{Re}(\mathrm{CO})_{5} \mathrm{Cl}$. During the reaction, the color of the suspension changed from pale yellow to orange, indicating the reaction between the MOF-253 and Re complex did occur. The XRD pattern of the as-synthesized product shows characteristic diffraction peaks of the MOF-253 framework, indicating that the introduction of the Re moiety does not influence the structure of MOF-253 (Fig. 1a). The slight decrease of the diffraction intensity of the resultant product as compared with the parent MOF-253 is probably due to the existence of disorder within the crystal structure of MOF-253 after the immobilization of the Re complex. The presence of Re species in the as-prepared product was confirmed by its FT-IR spectrum (Fig. 1b). As compared with the parent MOF-253, four additional peaks at $2027 \mathrm{~cm}^{-1}, 2024 \mathrm{~cm}^{-1}, 1920 \mathrm{~cm}^{-1}$ and $1903 \mathrm{~cm}^{-1}$ assignable to the asymmetric vibration of $\mathrm{CO}$ are observed, indicative of the formation of $\mathrm{MOF}-253-\operatorname{Re}(\mathrm{CO})_{3} \mathrm{Cl}$. The coordination of $\mathrm{Re}^{\mathrm{I}}$ to free $\mathrm{N}$, $\mathrm{N}$ '-chelating sites in MOF-253 leads to a slight red shift of the asymmetric vibration of $\mathrm{CO}$ as compared with those in the original $\operatorname{Re}(\mathrm{CO})_{5} \mathrm{Cl}$, which locates in $2060 \mathrm{~cm}^{-1}$, $2036 \mathrm{~cm}^{-1}$ and $1971 \mathrm{~cm}^{-1}, 1959 \mathrm{~cm}^{-1}$. The introduction of Re species into MOF-253 leads to a slightly decrease of the Langmuir surface area from the original $1489 \mathrm{~cm}^{3} / \mathrm{g}$ for pristine MOF-253 to $973 \mathrm{~cm}^{3} / \mathrm{g}$ for MOF-253- $\mathrm{Re}(\mathrm{CO})_{3} \mathrm{Cl}$, which can be attributed to the partial blocking of the pores in MOF-253 by the Re carbonyl complex. The relatively high Langmuir specific surface area of $\mathrm{MOF}-253-\mathrm{Re}(\mathrm{CO})_{3} \mathrm{Cl}$ still indicates the existence of the permanent porosity and the framework of MOF-253 is retained 
(Fig. 1c). ICP of the digested MOF sample gave a Re/Al molar ratio of $14.9 \%$ in the as-obtained MOF-253- $\operatorname{Re}(\mathrm{CO})_{3} \mathrm{Cl}$, which is a little lower than that added into the reaction system (with $\mathrm{Re} / \mathrm{Al}$ at 20\%). All these suggested that MOF-253- $\mathrm{Re}(\mathrm{CO})_{3} \mathrm{Cl}$ had successfully been obtained

The UV-vis DRS spectrum of the as-obtained MOF-253- $\mathrm{Re}(\mathrm{CO})_{3} \mathrm{Cl}$, together with that of pure MOF-253 and $\operatorname{Re}(\mathrm{dcbpy})(\mathrm{CO})_{3} \mathrm{Cl}$, are shown in Fig. 1d. In accordance with its yellow color in solution, homogeneous $\mathrm{Re}(\mathrm{dcbpy})(\mathrm{CO})_{3} \mathrm{Cl}$ shows an absorption centering at $390 \mathrm{~nm}$ and extends to $476 \mathrm{~nm}$, which can be assigned to the metal-to-ligand ( $\operatorname{Re}^{\mathrm{I}}$ to $\pi^{*}$ of bipyridine) charge transfer (MLCT). Pure MOF-253 alone does not show absorption in the visible light region. However, when MOF-253 was coordinated to $\operatorname{Re}(\mathrm{I})$ via the open $\mathrm{N}$, N'-chelating sites, the as-prepared MOF-253- $\mathrm{Re}(\mathrm{CO})_{3} \mathrm{Cl}$ shows absorption centering at $395 \mathrm{~nm}$ and extends to $540 \mathrm{~nm}$. As compared with homogeneous $\operatorname{Re}(\mathrm{dcbpy})(\mathrm{CO})_{3} \mathrm{Cl}$, a red shift was observed, indicative of the existence of strong interaction between $\left[\mathrm{Re}(\mathrm{CO})_{3} \mathrm{Cl}\right]$ moiety and MOF-253 framework.

Considering that diimine containing Re carbonyl complexes are good catalysts for $\mathrm{CO}_{2}$ reduction, the performance for photocatalytic $\mathrm{CO}_{2}$ reduction over the as-obtained MOF-253- $\mathrm{Re}(\mathrm{CO})_{3} \mathrm{Cl}$ was investigated. [58-60] The reaction was initially carried out in a $\mathrm{CO}_{2}$ saturated mixed solvent of $\mathrm{DMF} / \mathrm{H}_{2} \mathrm{O}(25 / 1)$ in the presence of triethanolamine (TEOA) as the sacrificial agent under visible light. Photocatalytic $\mathrm{CO}_{2}$ reduction over the as-prepared MOF-253- $\mathrm{Re}(\mathrm{CO})_{3} \mathrm{Cl}$ produced $\mathrm{HCOO}^{-}, \mathrm{CO}$ and little $\mathrm{H}_{2}$, the amount of all the products increased with the irradiation time( Fig. 2a). After 4 h about $9.50 \mu \mathrm{mol}$ of $\mathrm{HCOO}^{-}, 2.23 \mu \mathrm{mol}$ of $\mathrm{CO}$ as well as $0.11 \mu \mathrm{mol}$ of $\mathrm{H}_{2}$ were produced, corresponding to TON for the formation of $\mathrm{HCOO}^{-}, \mathrm{CO}$ and $\mathrm{H}_{2}$ to be 10.0, 2.4 and 0.1 , respectively (Table 1 , entry 1 ). No products were detected over pure MOF-253 or MOF-253- $\mathrm{Re}(\mathrm{CO})_{3} \mathrm{Cl}$ without light irradiation (Table 1, entry 2 and 3), indicating that the formation of the products was induced by photocatalysis over MOF-253- $\mathrm{Re}(\mathrm{CO})_{3} \mathrm{Cl}$. Only $0.22 \mu \mathrm{mol}$ of $\mathrm{H}_{2}(\mathrm{TON}=0.23)$ was produced under the $\mathrm{N}_{2}$ atmosphere, implying that $\mathrm{CO}$ and $\mathrm{HCOO}^{-}$came from the reduction of $\mathrm{CO}_{2}$ (Table 1, entry 4). The reaction medium as well as the sacrificial agent influenced the photocatalytic activity. The change of the solvent from DMF to THF led to a decrease 
of the t-TON (t-TON for total TON of the produced $\mathrm{CO}$ and $\mathrm{HCOO}^{-}$) from 12.37 to 5.77 (Table 1, entry 5). Sacrificial agent play an important role in the photoctalytic $\mathrm{CO}_{2}$ reduction since a much lower t-TON (1.58) was obtained when the sacrificial agent TEOA was replaced by TEA and no products were detected in absence of the sacrificial agent (Table 1, entry 6, 7). Although $\mathrm{CO}_{2}$ can be photocatalytic reduced over homogeneous $\operatorname{Re}(\mathrm{dcbpy})(\mathrm{CO})_{3} \mathrm{Cl}$, the main product obtained was $\mathrm{CO}$ and in $4 \mathrm{~h}$, a t-TON of 9.37 were obtained (Table 1, entry 8).

As compared with the homogeneous $\operatorname{Re}(\mathrm{dcbpy})(\mathrm{CO})_{3} \mathrm{Cl}, \mathrm{MOF}-253-\mathrm{Re}(\mathrm{CO})_{3} \mathrm{Cl}$ showed higher stability during the photocatalytic $\mathrm{CO}_{2}$ reduction. The amount of all the products increased with the irradiation time and a t-TON of 24.35 for photocatalytic $\mathrm{CO}_{2}$ reduction was obtained in $16 \mathrm{~h}$ (Fig. 2b). Although the ICP analysis revealed that about $1.6 \%$ of the incorporated Re leached into the reaction filtrate, the filtrate experiment showed no more $\mathrm{HCOO}^{-}$were produced and none $\mathrm{CO}$ was detected when the filtrate was irradiated for another $4 \mathrm{~h}$ (Fig. 2a), a confirmation of the heterogeneous nature of the MOF-253- $\mathrm{Re}(\mathrm{CO})_{3} \mathrm{Cl}$ in the photocatalytic $\mathrm{CO}_{2}$ reduction. Moreover, the XRD of the MOF-253- $\mathrm{Re}(\mathrm{CO})_{3} \mathrm{Cl}$ did not change obviously after the reaction (Fig 3). All these observations indicated that $\mathrm{MOF}-253-\mathrm{Re}(\mathrm{CO})_{3} \mathrm{Cl}$ is stable during photocatalytic $\mathrm{CO}_{2}$ reduction. However, the color of the homogeneous $\mathrm{Re}(\mathrm{dcbpy})(\mathrm{CO})_{3} \mathrm{Cl}$ reaction system changed gradually from the original yellow to colorless during the reaction and the amount of the produced CO did not increase after $4 \mathrm{~h}$ irradiations, indicating the deactivation of the homogeneous Re complex (Fig 2b).

Previous studies indicated that the deactivation of the homogeneous $\operatorname{Re}(\mathrm{N}$, $\left.\mathrm{N}^{\prime}\right)(\mathrm{CO})_{3} \mathrm{Cl}$ during $\mathrm{CO}_{2}$ reduction is induced by the formation of the inactive bimolecular $\left[\mathrm{Re}\left(\mathrm{N}, \mathrm{N}^{\prime}\right)(\mathrm{CO})_{3}\right]_{2} \mathrm{OCO}_{2}$. [57, 61] It is generally believed that when homogeneous $\operatorname{Re}\left(\mathrm{N}, \mathrm{N}^{\prime}\right)(\mathrm{CO})_{3} \mathrm{Cl}$ is excited, the dissociation of $\mathrm{Cl}^{-}$gives penta-coordinated $\left[\operatorname{Re}\left(\mathrm{N}, \mathrm{N}^{\prime}\right)(\mathrm{CO})_{3}\right]$ as the intermediate, which can reduce $\mathrm{CO}_{2}$ to give $\mathrm{CO}$ via two pathways. [47, 62, 63] The predominant pathway involves a very fast $\mathrm{CO}_{2}$ addition to generate a $\mathrm{CO}_{2}$ bridged $\left[\mathrm{Re}\left(\mathrm{N}, \mathrm{N}^{\prime}\right)(\mathrm{CO})_{3}\right]_{2} \mathrm{C}(\mathrm{O}) \mathrm{O}$, which followed by the addition of another $\mathrm{CO}_{2}$ and the release of $\mathrm{CO}$ to give the inactive $[\operatorname{Re}(\mathrm{N}$, $\left.\mathrm{N}^{\prime}(\mathrm{CO})_{3}\right]_{2} \mathrm{OCO}_{2}$ and terminate the reaction. Another slow pathway, ie, non-dominant one, is the addition of $\mathrm{CO}_{2}$ to $\left[\operatorname{Re}\left(\mathrm{N}, \mathrm{N}^{\prime}\right)(\mathrm{CO})_{3}\right]$ to generate $\operatorname{Re}\left(\mathrm{N}, \mathrm{N}^{\prime}\right)(\mathrm{CO})_{3} \mathrm{COOH}$, which can also release $\mathrm{CO}$ and return back to $\left[\mathrm{Re}\left(\mathrm{N}, \mathrm{N}^{\prime}\right)(\mathrm{CO})_{3} \mathrm{Cl}\right]$. Since the 
predominant pathway during the $\mathrm{CO}_{2}$ reduction over homogeneous $\operatorname{Re}\left(\mathrm{N}, \mathrm{N}^{\prime}\right)(\mathrm{CO})_{3} \mathrm{Cl}$ give the nonactive bimolecular $\left[\operatorname{Re}\left(\mathrm{N}, \mathrm{N}^{\prime}\right)(\mathrm{CO})_{3}\right]_{2} \mathrm{C}(\mathrm{O}) \mathrm{O}$, homogeneous $\operatorname{Re}$ complexes deactivate very fast during the photocatalytic $\mathrm{CO}_{2}$ reduction (Scheme 1)

On the contrary, although light irradiation on $\mathrm{MOF}-253-\mathrm{Re}(\mathrm{CO})_{3} \mathrm{Cl}$ also lead to the one-electron reduced species $\left[\mathrm{MOF}-253-\mathrm{Re}(\mathrm{CO})_{3}\right]$ by releasing a $\mathrm{Cl}^{-}$, two spatially isolated $\left[\left(\mathrm{N}, \mathrm{N}^{\prime}\right)-\operatorname{Re}(\mathrm{CO})_{3}\right]$ in $\mathrm{MOF}-253$ cannot be bridged by $\mathrm{CO}_{2}$ to generate the non-active bimolecular $\left[\mathrm{MOF}-253-\operatorname{Re}(\mathrm{CO})_{3}\right]_{2} \mathrm{C}(\mathrm{O}) \mathrm{O}$. Therefore, the deactivation of the active $\operatorname{Re}$ species by forming the inactive bimolecular $\left[\mathrm{MOF}-253-\mathrm{Re}(\mathrm{CO})_{3}\right]_{2} \mathrm{OCO}_{2}$ can be significantly inhibited in the surface supported $\mathrm{Re}$ complexes. However, the direct $\mathrm{CO}_{2}$ adduction into the Re-hydride $\left[\mathrm{MOF}-253-\mathrm{Re}(\mathrm{CO})_{3} \mathrm{H}\right]$ is possible to form $\left[\mathrm{MOF}-253-\mathrm{Re}(\mathrm{CO})_{3} \mathrm{OCHO}\right]$, which leads to the production of $\mathrm{HCOO}^{-}$and recover the [MOF-253-Re(CO) ${ }_{3} \mathrm{Cl}$ ]. [64] Although no production of $\mathrm{HCOO}^{-}$was isolated during the photocatalytic $\mathrm{CO}_{2}$ reduction over homogeneous $\operatorname{Re}\left(\mathrm{N}, \mathrm{N}^{\prime}\right)(\mathrm{CO})_{3} \mathrm{Cl}$, the study by Hawecker et. al. directly observed the formate-intermediate $\operatorname{Re}\left(\mathrm{N}, \mathrm{N}^{\prime}\right)(\mathrm{CO})_{3} \mathrm{OCHO}$. [17] In addition, $\mathrm{Re}$ hydride intermediate $\mathrm{Re}\left(\mathrm{N}, \mathrm{N}^{\prime}\right)(\mathrm{CO})_{3} \mathrm{H}$ has previously been used for $\mathrm{CO}_{2}$ reduction to produce $\mathrm{HCOO}^{-}$. [65] A non-dominant pathway also exists to produce $\mathrm{CO}$ via the addition of $\mathrm{CO}_{2}$ to $\left[\mathrm{MOF}-253-\operatorname{Re}(\mathrm{CO})_{3}\right]$ for generating $\mathrm{MOF}-253-\mathrm{Re}(\mathrm{CO})_{3} \mathrm{COOH}$, which is similar to that observed in homogeneous $\mathrm{Re}\left(\mathrm{N}, \mathrm{N}^{\prime}\right)(\mathrm{CO})_{3} \mathrm{Cl}$ system. Since the direct addition of $\mathrm{CO}_{2}$ to $\left[\mathrm{MOF}-253-\mathrm{Re}(\mathrm{CO})_{3}\right]$ is slow, the main product from $\mathrm{CO}_{2}$ reduction over MOF-253- $\mathrm{Re}(\mathrm{CO})_{3} \mathrm{Cl}$ is $\mathrm{HCOO}^{-}$(Scheme 2).

The above mechanism for photocatalytic $\mathrm{CO}_{2}$ reduction was verified by the reaction carried out using ${ }^{13} \mathrm{CO}_{2}$. The GC-MS spectra of the gaseous product from the reaction with ${ }^{13} \mathrm{CO}_{2}$ show signals at $\mathrm{m} / \mathrm{z}$ values of 29 and 28 , corresponding to ${ }^{13} \mathrm{CO}$ and ${ }^{12} \mathrm{CO}$ respectively. In contrast, only the signal at the $\mathrm{m} / \mathrm{z}$ value of 28 was detected in the product from the reaction with ${ }^{12} \mathrm{CO}_{2}$. This clearly indicates that $\mathrm{CO}_{2}$ was reduced to $\mathrm{CO}$ over MOF-253- $\mathrm{Re}(\mathrm{CO})_{3} \mathrm{Cl}$ (Supporting Fig. 1). The coexistence of ${ }^{12} \mathrm{CO}$ in the gaseous product in the ${ }^{13} \mathrm{CO}_{2}$ reaction may come from those dissociated from the MOF-253- $\mathrm{Re}(\mathrm{CO})_{3} \mathrm{Cl}$ as elucidated in the mechanism. Also the $\mathrm{HCOO}^{-}$is originated from $\mathrm{CO}_{2}$ as evidenced from the ${ }^{13} \mathrm{C}$ NMR spectrum (Supporting Fig. 2).

The disadvantage of using $\left[\operatorname{Re}\left(\mathrm{N}, \mathrm{N}^{\prime}\right)(\mathrm{CO})_{3} \mathrm{X}\right]$ complexes for photocatalytic $\mathrm{CO}_{2}$ 
reduction is their poor light absorption in the visible light region. The coupling of a $\mathrm{Ru}$ photosensitizer to the $\mathrm{Re}$ catalyst via building $\mathrm{Ru}(\mathrm{II})-\operatorname{Re}(\mathrm{I})$ supramolecules have been demonstrated to be an effective method to improve their photocatalytic performance for $\mathrm{CO}_{2}$ reduction under visible light. [66-68] However, the syntheses of the supramolecules are usually challenging and require tedious process. MOFs provides an appealing platform for assembly of different active components into an efficient composite photocatalytic system due to its highly ordered crystalline structure, which can promote the charge transfer between the photosensitizer and the surface constructed catalyst. [69-72] That is to say the tailorable character of MOFs allows a huge flexibility to assemble multi-functional material for applications. [41, 73-76] Therefore, to further improve the light absorption of $\mathrm{MOF}-253-\mathrm{Re}(\mathrm{CO})_{3} \mathrm{Cl}$, $\mathrm{Ru}(\mathrm{bpy})_{2} \mathrm{Cl}_{2}$ was used to prepared photo-sensitized $\mathrm{MOF}-253-\mathrm{Re}(\mathrm{CO})_{3} \mathrm{Cl}$ since $\mathrm{Ru}$ (bpy) ${ }_{2} \mathrm{Cl}_{2}$ can also react with the surface $\mathrm{N}, \mathrm{N}^{\prime}$-chelate sites to form MOF-253 supported $\left[\mathrm{Ru}\left(\mathrm{N}, \mathrm{N}^{\prime}\right)(\mathrm{bpy}) 2_{2}{ }^{2+}\right]$, which shows absorption in visible light region. [55] As shown in Fig 1d, sensitized-MOF-253- $\mathrm{Re}(\mathrm{CO})_{3} \mathrm{Cl}$ shows enhanced absorption in visible light region, with the absorption edge extending to $648 \mathrm{~nm}$. The formation of $\left[\mathrm{Ru}\left(\mathrm{N}, \mathrm{N}^{\prime}\right)(\mathrm{bpy}) 2^{2+}\right]$ was also confirmed by the higher catalytic activity over MOF-253 supported $\mathrm{Ru}(\mathrm{bpy})_{2} \mathrm{Cl}_{2}$ (MOF-253-Ru) (TON of $\mathrm{HCOO}^{-}$and $\mathrm{CO}$ to be 0.6 and 0.08 , respectively) than that over pure $\mathrm{Ru}(\mathrm{bpy})_{2} \mathrm{Cl}_{2}$ with $\mathrm{TON}$ of $\mathrm{HCOO}^{-}$and $\mathrm{CO}$ to be 0.1 and 0.02 ) under similar conditions (Table 1, entry 10 and 11). The photocatalytic activity over the sensitized-MOF-253- $\mathrm{Re}(\mathrm{CO})_{3} \mathrm{Cl}$ was found to increase significantly as compared with the non-sensitized one. The TON of $\mathrm{HCOO}^{-}$, $\mathrm{CO}$ and $\mathrm{H}_{2}$ produced in $4 \mathrm{~h}$ over sensitized MOF-253- $\mathrm{Re}(\mathrm{CO})_{3} \mathrm{Cl}$, with a molar ratio of $\mathrm{Ru}(\text { bpy })_{2} \mathrm{Cl}_{2} / \mathrm{Re}$-complex at $1: 32$, was determined to be $23.26,5.40$ and 0.99 , nearly twice higher than MOF-253- $\mathrm{Re}(\mathrm{CO})_{3} \mathrm{Cl}$ under similar conditions (Fig 4). ICP analyses showed that about $1.4 \%$ of $\mathrm{Ru}$ leached into the solution after $4 \mathrm{~h}$ of irradiation. However, the amount of $\mathrm{Ru}$ leaching into solution did not influence the photocatalytic activity since homogeneous $\mathrm{Ru}(\mathrm{bpy})_{2} \mathrm{Cl}_{2}$ exhibited low activity under similar conditions (Table 1, entry 11). These indicates that the photocatalytic $\mathrm{CO}_{2}$ reduction did occur over heterogeneous sensitized-MOF-253-Re $(\mathrm{CO})_{3} \mathrm{Cl}$. It is means that MOF-253 can act as a multifunction plantform to supported photocatalyst $\mathrm{Re}$ complex and photosensitizer Ru complex to construct a stable hybrid photocatalysis 
system, which can promote the charge transfer between the photosensitizer and the photocatalyst.

\section{Conclusions}

In summary, MOF-253 surface constructed Re carbonyl complex MOF-253- $\mathrm{Re}(\mathrm{CO})_{3} \mathrm{Cl}$ shows superior photocatalytic performance for $\mathrm{CO}_{2}$ reduction under visible light irradiation as compared with its homogeneouscounterpart. In addition, a surface supported $\mathrm{Ru}$ sensitizer was simultaneously constructed in MOF-253- $\mathrm{Re}(\mathrm{CO})_{3} \mathrm{Cl}$ to give a sensitized-MOF-253- $\mathrm{Re}(\mathrm{CO})_{3} \mathrm{Cl}$, which shows a superior performance for photocatalytic $\mathrm{CO}_{2}$ reduction under visible light via an efficient charge transfer from $\mathrm{Ru}$ sensitizer to $\mathrm{Re}$ catalytic center. This work highlights the great potential of using MOFs both as a solid ligand to build a supported molecular catalyst and as a platform for assembly of several active moieties into one composite system to achieve complicated functions.

\section{Acknowledgments}

This work was supported by 973 Program (2014CB239303), NSFC (21273035) and Independent Research Project of State Key Laboratory of Photocatalysis on Energy and Environment (2014A03). Z. Li also thanks the Award Program for Minjiang Scholar Professorship for financial support. 


\section{Reference}

[1] Song C 2006 Global challenges and strategies for control, conversion and utilization of $\mathrm{CO}_{2}$ for sustainable development involving energy, catalysis, adsorption and chemical processing Catal. Today 115 2-32

[2] Lewis N S and Nocera D G 2006 Powering the planet: Chemical challenges in solar energy utilization Proc. Nat.l Acad. Sci. 103 15729-35

[3] Fontecave M 2011 Energy for a Sustainable World. From the Oil Age to a Sun-Powered Future. By Nicola Armaroli and Vincenzo Balzani Angew. Chem. Int. Edit. 50 6704-5

[4] Appel A M, Bercaw J E, Bocarsly A B, Dobbek H, DuBois D L, Dupuis M, Ferry J G, Fujita E, Hille R, Kenis P J, Kerfeld C A, Morris R H, Peden C H, Portis A R, Ragsdale S W, Rauchfuss T B, Reek J N, Seefeldt L C, Thauer R K and Waldrop G L 2013 Frontiers, opportunities, and challenges in biochemical and chemical catalysis of $\mathrm{CO}_{2}$ fixation Chem. Rev. $1136621-58$

[5] Habisreutinger S N, Schmidt-Mende L and Stolarczyk J K 2013 Photocatalytic reduction of $\mathrm{CO}_{2}$ on $\mathrm{TiO}_{2}$ and other semiconductors Angew. Chem. Int. Edit. 52 7372-408

[6] Chang $\mathrm{X}$, Wang $\mathrm{T}$ and Gong $\mathrm{J} 2016 \mathrm{CO}_{2}$ photo-reduction: insights into $\mathrm{CO}_{2}$ activation and reaction on surfaces of photocatalysts Energy Environ. Sci. 9 2177-96

[7] Liu X, Inagaki S and Gong J 2016 Heterogeneous Molecular Systems for Photocatalytic $\mathrm{CO}_{2}$ Reduction with Water Oxidation Angew. Chem. Int. Edit. 55 14924-50

[8] White J L, Baruch M F, Pander lii J E, Hu Y, Fortmeyer I C, Park J E, Zhang T, Liao K, Gu J, Yan Y, Shaw T W, Abelev E and Bocarsly A B 2015 Light-Driven Heterogeneous Reduction of Carbon Dioxide: Photocatalysts and Photoelectrodes Chem. Rev. 115 12888-935

[9] Ashford D L, Gish M K, Vannucci A K, Brennaman M K, Templeton J L, Papanikolas J M and Meyer T J 2015 Molecular Chromophore-Catalyst Assemblies for Solar Fuel Applications Chem. Rev. 115 13006-49

[10] Tu W, Zhou Y and Zou Z 2014 Photocatalytic conversion of $\mathrm{CO}_{2}$ into renewable hydrocarbon fuels: state-of-the-art accomplishment, challenges, and prospects Adv. Mater. 26 4607-26

[11] Marszewski M, Cao S, Yu J and Jaroniec M 2015 Semiconductor-based photocatalytic $\mathrm{CO}_{2}$ conversion Mater. Horiz. 2 261-78

[12] Kotch T G, Lees A J, Fuerniss S J and Papathomas K I 1992 Luminescent organometallic complexes as visible probes in the isothermal curing of epoxy resins Chem. Mater. 4 $675-83$

[13] Kumar B, Smieja J M and Kubiak C P 2010 Photoreduction of $\mathrm{CO}_{2}$ on p-type Silicon Using Re (bipy-Bu- $t)(\mathrm{CO})_{3} \mathrm{Cl}$ : Photovoltages Exceeding $600 \mathrm{mV}$ for the Selective Reduction of $\mathrm{CO}_{2}$ to CO J. Phys. Chem. C 114 14220-3

[14] Smieja J M and Kubiak C P 2010 Re(bipy-tBu)(CO) $)_{3}$ Cl-improved catalytic activity for 
reduction of carbon dioxide: IR-spectroelectrochemical and mechanistic studies Inorg. Chem. 49 9283-9

[15] Kumar B, Llorente M, Froehlich J, Dang T, Sathrum A and Kubiak C P 2012 Photochemical and photoelectrochemical reduction of $\mathrm{CO}_{2}$ Annu. Rev. Phys. Chem. 63 541-69

[16] Portenkirchner E, Apaydin D, Aufischer G, Havlicek M, White M, Scharber M C and Sariciftci N S 2014 Photoinduced energy transfer from poly(N-vinylcarbazole) to tricarbonylchloro-(2,2'-bipyridyl)rhenium(I) Chemphyschem 15 3634-8

[17] Hawecker J, Lehn J M and Ziessel R 1986 Photochemical and Electrochemical Reduction of Carbon Dioxide to Carbon Monoxide Mediated by (2, 2'-Bipyridine) tricarbonylchlororhenium (I) and Related Complexes as Homogeneous Catalysts Helv. Chim. Acta 69 1990-2012

[18] Juris A, Campagna S, Bidd I, Lehn J M and Ziessel R 1988 Synthesis and photophysical and electrochemical properties of new halotricarbonyl(polypyridine)rhenium(I) complexes Inorg. Chem. 27 4007-11

[19] Ali N M, MacLeod V L, Jennison P, Sazanovich I V, Hunter C A, Weinstein J A and Ward M D 2012 Luminescent cyanometallates based on phenylpyridine-Ir(III) units: solvatochromism, metallochromism, and energy-transfer in Ir/Ln and Ir/Re complexes Dalton Trans. 41 2408-19

[20] Ohkubo K, Yamazaki Y, Nakashima T, Tamaki Y, Koike K and Ishitani O 2016 Photocatalyses of $\mathrm{Ru}(\mathrm{II})-\mathrm{Re}(\mathrm{I})$ binuclear complexes connected through two ethylene chains for $\mathrm{CO}_{2}$ reduction J. Cata. $\mathbf{3 4 3} 278-89$

[21] Sahara G, Kumagai H, Maeda K, Kaeffer N, Artero V, Higashi M, Abe R and Ishitani O 2016 Photoelectrochemical Reduction of $\mathrm{CO}_{2}$ Coupled to Water Oxidation Using a Photocathode With a $\mathrm{Ru}(\mathrm{II})-\mathrm{Re}(\mathrm{I})$ Complex Photocatalyst and a CoOx/TaON Photoanode J. Am. Chem. Soc.

[22] Fan Y, Zhang L Y, Dai F R, Shi L X and Chen Z N 2008 Preparation, Characterization, and Photophysical Properties of $\mathrm{Pt}-\mathrm{M}(\mathrm{M}=\mathrm{Ru}, \mathrm{Re})$ Heteronuclear Complexes with 1,10-Phenanthrolineethynyl Ligands Inorg. Chem. 47 2811-9

[23] Shankar B, Arumugam R, Elumalai P and Sathiyendiran M 2016 Rhenium(I)-Based Monocyclic and Bicyclic Phosphine Oxide-Coordinated Supramolecular Complexes ACS Omega 1 507-17

[24] Cavigli P, Balducci G, Zangrando E, Demitri N, Amati A, Indelli M T and Iengo E 2016 Structural and photophysical characterization of a tin(IV) porphyrin-rhenium(I)(diimine) conjugate Inorg. Chim. Acta 439 61-8

[25] Wang C, Xie Z, deKrafft K E and Lin W 2011 Doping metal-organic frameworks for water oxidation, carbon dioxide reduction, and organic photocatalysis J. Am. Chem. Soc.

$13313445-54$ 
[26] Windle C D, Pastor E, Reynal A, Whitwood A C, Vaynzof Y, Durrant J R, Perutz R N and Reisner E 2015 Improving the photocatalytic reduction of $\mathrm{CO} 2$ to $\mathrm{CO}$ through immobilisation of a molecular Re catalyst on TiO2 Chem. Eur. J. 21 3746-54

[27] Wang X, Shi H, Kwak J H and Szanyi J 2015 Mechanism of $\mathrm{CO}_{2}$ Hydrogenation on $\mathrm{Pd} / \mathrm{Al}_{2} \mathrm{O}_{3}$ Catalysts: Kinetics and Transient DRIFTS-MS Studies ACS Catal. 5 6337-49

[28] Wu F, Feng Y and Jones C W 2014 Recyclable Silica-Supported Iridium Bipyridine Catalyst for Aromatic C-H Borylation ACS Catal. 4 1365-75

[29] Corma A, Garcia H and Xamena F X L I 2010 Engineering Metal Organic Frameworks for Heterogeneous Catalysis Chem. Rev. 110 4606-55

[30] Van de Voorde B, Bueken B, Denayer J and De Vos D 2014 Adsorptive separation on metal-organic frameworks in the liquid phase Chem. Soc. Rev. 43 5766-88

[31] Furukawa H, Cordova K E, O'Keeffe M and Yaghi O M 2013 The chemistry and applications of metal-organic frameworks Science 3411230444

[32] Suh M P, Park H J, Prasad T K and Lim D W 2012 Hydrogen storage in metal-organic frameworks Chem. Rev. 112 782-835

[33] Zhou H C, Long J R and Yaghi O M 2012 Introduction to metal-organic frameworks Chem. Rev. 112 673-4

[34] Xuan W, Zhu C, Liu Y and Cui Y 2012 Mesoporous metal-organic framework materials Chem. Soc. Rev. 41 1677-95

[35] Gao W Y, Chrzanowski M and Ma S 2014 Metal-metalloporphyrin frameworks: a resurging class of functional materials Chem. Soc. Rev. 43 5841-66

[36] Lee J, Farha O K, Roberts J, Scheidt K A, Nguyen S T and Hupp J T 2009 Metal-organic framework materials as catalysts Chem. Soc. Rev. 38 1450-9

[37] Kreno L E, Leong K, Farha O K, Allendorf M, Van Duyne R P and Hupp J T 2012 Metal-organic framework materials as chemical sensors Chem. Rev. 112 1105-25

[38] Zhou H C and Kitagawa S 2014 Metal-organic frameworks (MOFs) Chem. Soc. Rev. 43 5415-8

[39] Li J R, Sculley J and Zhou H C 2012 Metal-organic frameworks for separations Chem. Rev. 112 869-932

[40] Horcajada P, Gref R, Baati T, Allan P K, Maurin G, Couvreur P, Ferey G, Morris R E and Serre C 2012 Metal-organic frameworks in biomedicine Chem. Rev. 112 1232-68

[41] Huang Y B, Liang J, Wang X S and Cao R 2017 Multifunctional metal-organic framework catalysts: synergistic catalysis and tandem reactions Chem. Soc. Rev. 46 $126-57$

[42] Jiang H L and Xu Q 2011 Porous metal-organic frameworks as platforms for functional applications Chem. Commun. 47 3351-70

[43] Stock N and Biswas S 2012 Synthesis of metal-organic frameworks (MOFs): routes to various MOF topologies, morphologies, and composites Chem. Rev. 112 933-69 
[44] Lu W, Wei Z, Gu Z Y, Liu T F, Park J, Park J, Tian J, Zhang M, Zhang Q and Rd G T 2014 Tuning the structure and function of metal-organic frameworks via linker design Chem. Soc. Rev. 43 5561-93

[45] He Y, Li B, O'Keeffe M and Chen B 2014 Multifunctional metal-organic frameworks constructed from meta-benzenedicarboxylate units Chem. Soc. Rev. 43 5618-56

[46] Bai C, Yao X and Li Y 2015 Easy Access to Amides through Aldehydic C-H Bond Functionalization Catalyzed by Heterogeneous Co-Based Catalysts ACS Catal. 5 884-91

[47] Fei H and Cohen S M 2015 Metalation of a thiocatechol-functionalized Zr(IV)-based metal-organic framework for selective C-H functionalization J. Am. Chem. Soc. 137 2191-4

[48] Cho S H, Ma B, Nguyen S T, Hupp J T and Albrecht-Schmitt T E 2006 A metal-organic framework material that functions as an enantioselective catalyst for olefin epoxidation Chem. Commun. 2563-5

[49] Horike S, Dinca M, Tamaki K and Long J R 2008 Size-selective Lewis acid catalysis in a microporous metal-organic framework with exposed Mn2+ coordination sites $J$. Am. Chem. Soc. 130 5854-5

[50] Li L, Zhang S, Xu L, Han L, Chen Z N and Luo J 2013 An intensely luminescent metal-organic framework based on a highly light-harvesting dyclo-metalated iridium(III) unit showing effective detection of explosives Inorg. Chem. 52 12323-5

[51] Fei H, Sampson M D, Lee Y, Kubiak C P and Cohen S M 2015 Photocatalytic $\mathrm{CO}_{2}$ Reduction to Formate Using a Mn(I) Molecular Catalyst in a Robust Metal-Organic Framework Inorg. Chem. 54 6821-8

[52] Bloch E D, Britt D, Lee C, Doonan C J, Uribe-Romo F J, Furukawa H, Long J R and Yaghi O M 2010 Metal insertion in a microporous metal- organic framework lined with 2, 2'-bipyridine J. Am. Chem. Soc. 132 14382-4

[53] Zhou T, Du Y, Borgna A, Hong J, Wang Y, Han J, Zhang W and Xu R 2013 Post-synthesis modification of a metal-organic framework to construct a bifunctional photocatalyst for hydrogen production Energy Environ. Sci. 63229

[54] Lu Y and Yan B 2014 Luminescent lanthanide barcodes based on postsynthetic modified nanoscale metal-organic frameworks J. Mater. Chem. C 27411

[55] Sun D, Gao Y, Fu J, Zeng X, Chen Z and Li Z 2015 Construction of a supported Ru complex on bifunctional MOF-253 for photocatalytic $\mathrm{CO} 2$ reduction under visible light Chem. Commun. $\mathbf{5 1} 2645-8$

[56] Gibson D H, Yin X, He H and Mashuta M S 2003 Synthesis and Reactions of fac-[Re $(\mathrm{dmbpy})(\mathrm{CO}) 3 \mathrm{X}](\mathrm{dmbpy}=4$, 4'-Dimethyl-2, 2'-bipyridine; $\mathrm{X}=\mathrm{COOH}, \mathrm{CHO})$ and Their Derivatives Organometallics 22 337-46

[57] Agarwal J, Fujita E, Schaefer H F, 3rd and Muckerman J T 2012 Mechanisms for CO production from $\mathrm{CO}_{2}$ using reduced rhenium tricarbonyl catalysts J. Am. Chem. Soc. 134 
$5180-6$

[58] Manbeck G F, Muckerman J T, Szalda D J, Himeda Y and Fujita E 2015 Push or Pull? Proton Responsive Ligand Effects in Rhenium Tricarbonyl $\mathrm{CO}_{2}$ Reduction Catalysts $J$. Phys. Chem. B 119 7457-66

[59] Bruckmeier C, Lehenmeier M W, Reithmeier R, Rieger B, Herranz J and Kavakli C 2012 Binuclear rhenium(I) complexes for the photocatalytic reduction of $\mathrm{CO}_{2}$ Dalton Trans. 41 5026-37

[60] Agarwal J, Sanders B C, Fujita E, Schaefer H F, 3rd, Harrop T C and Muckerman J T 2012 Exploring the intermediates of photochemical $\mathrm{CO}_{2}$ reduction: reaction of $\mathrm{Re}(\mathrm{dmb})(\mathrm{CO}){ }_{3} \mathrm{COOH}$ with $\mathrm{CO}_{2}$ Chem. Commun. 48 6797-9

[61] Takeda H, Koike K, Inoue H and Ishitani O 2008 Development of an efficient photocatalytic system for $\mathrm{CO}_{2}$ reduction using rhenium (I) complexes based on mechanistic studies J. Am. Chem. Soc. 130 2023-31

[62] Gibson D H and Yin X 1998 Synthesis and Reactions of fac-Re (dmbpy)(CO) $)_{3} \mathrm{X}(\mathrm{dmbpy}=$ 4, 4'-dimethyl-2, 2'-bipyridyl; $\mathrm{X}=\mathrm{COOH}, \mathrm{COOMe}, \mathrm{H}, \mathrm{OH}$, and $\mathrm{OCHO}) \mathrm{J}$. Am. Chem. Soc. 120 11200-1

[63] Schneider T W, Ertem M Z, Muckerman J T and Angeles-Boza A M 2016 Mechanism of Photocatalytic Reduction of $\mathrm{CO}_{2}$ by $\mathrm{Re}(\mathrm{bpy})(\mathrm{CO})_{3} \mathrm{Cl}$ from Differences in Carbon Isotope Discrimination ACS Catal. 6 5473-81

[64] Grills D C and Fujita E 2010 New Directions for the Photocatalytic Reduction of $\mathrm{CO}_{2}$ : Supramolecular, $\mathrm{scCO}_{2}$ or Biphasic Ionic Liquid- $\mathrm{scCO}_{2}$ Systems J. Phys. Chem. Lett. 1 2709-18

[65] Sullivan B P and Meyer T J 1986 Kinetics and mechanism of carbon dioxide insertion into a metal-hydride bond. A large solvent effect and an inverse kinetic isotope effect Organometallics 5 1500-2

[66] Yamamoto Y, Tamaki Y, Yui T, Koike K and Ishitani O 2010 New Light-Harvesting Molecular Systems Constructed with a Ru (II) Complex and a Linear-Shaped Re (I) Oligomer J. Am. Chem. Soc. 132 11743-52

[67] Nakada A, Koike K, Nakashima T, Morimoto T and Ishitani O 2015 Photocatalytic $\mathrm{CO}_{2}$ reduction to formic acid using a $\mathrm{Ru}(\mathrm{II})-\mathrm{Re}(\mathrm{I})$ supramolecular complex in an aqueous solution Inorg. Chem. 54 1800-7

[68] Nakada A, Koike K, Maeda K and Ishitani O 2016 Highly efficient visible-light-driven $\mathrm{CO}_{2}$ reduction to $\mathrm{CO}$ using a $\mathrm{Ru}(\mathrm{ii})-\mathrm{Re}(\mathrm{i})$ supramolecular photocatalyst in an aqueous solution Green Chem. 18 139-43

[69] Crake A, Christoforidis K C, Kafizas A, Zafeiratos S and Petit C $2017 \mathrm{CO}_{2}$ capture and photocatalytic reduction using bifunctional $\mathrm{TiO}_{2} / \mathrm{MOF}$ nanocomposites under $\mathrm{UV}$-vis irradiation Appl. Cata. B-Environ 210 131-40

[70] Wang J L, Wang C and Lin W 2017 Metal-Organic Frameworks for Light Harvesting and 
Photocatalysis Acs Catal. 2 2630-40

[71] Sun D and Li Z 2017 Robust Ti- and Zr-Based Metal-Organic Frameworks for Photocatalysis Chin. J. Chem. 35 135-47

[72] Alvaro M, Carbonell E, Ferrer B, Llabrés i Xamena F X and Garcia H 2007 Semiconductor Behavior of a Metal-Organic Framework (MOF) Chem. Eur. J. 13 5106-12

[73] Gao X, Zhai M, Guan W, Liu J, Liu Z and Damirin A 2017 Controllable Synthesis of a Smart Multifunctional Nanoscale Metal-Organic Framework for Magnetic Resonance/Optical Imaging and Targeted Drug Delivery ACS Appl. Mater. Inter. 9 $3455-62$

[74] Qin J-S, Yuan S, Wang Q, Alsalme A and Zhou H-C 2017 Mixed-linker strategy for the construction of multifunctional metal-organic frameworks J. Mater. Chem. A 5 4280-91

[75] Pullen S and Ott S 2016 Photochemical Hydrogen Production with Metal-Organic Frameworks Top. Catal. 59 1712-21

[76] Deng X, Li Z and Garcia H 2017 Visible Light Induced Organic Transformations Using Metal-Organic-Frameworks (MOFs) Chem. Eur. J. 23 1-22 


\section{Captions for Figures}

Fig. 1 (a). XRD patterns of the as-obtained MOF-253 (i), MOF-253- $\mathrm{Re}(\mathrm{CO})_{3} \mathrm{Cl}$ (ii), sensitized-MOF-253- $\mathrm{Re}(\mathrm{CO})_{3} \mathrm{Cl}$ (iii)MOF-253 and calculated MOF-253 (iv). (b). FT-IR spectra of $\mathrm{MOF}-253-\mathrm{Re}(\mathrm{CO})_{3} \mathrm{Cl} \quad$ (i) and $\mathrm{Re}(\mathrm{CO})_{5} \mathrm{Cl}$ (ii). (c). $\mathrm{N}_{2}$ adsorption/desorption isotherms $(77 \mathrm{~K})$ of $\mathrm{MOF}-253-\mathrm{Re}(\mathrm{CO})_{3} \mathrm{Cl}(\mathrm{i})$ and $\operatorname{Re}(\mathrm{CO})_{5} \mathrm{Cl}$ (ii). (d). UV/Vis DRS spectra of MOF-253 (Solid line), MOF-253-Re(CO) 3 Cl(Dot line) and sensitized-MOF-253- $\mathrm{Re}(\mathrm{CO})_{3} \mathrm{Cl}$ (Dash line), UV/Vis absorption spectrum of homogeneous $\mathrm{Re}(\mathrm{dcbpy})(\mathrm{CO})_{3} \mathrm{Cl}$ (Inset figure).

Fig. 2 (a). The respective TON of $\mathrm{H}_{2}(\boldsymbol{\bullet}), \mathrm{CO}(\bullet), \mathrm{HCOO}^{-}$(ム) over MOF-253- $\operatorname{Re}(\mathrm{CO})_{3} \mathrm{Cl}$ and the t-TON $(\triangle)$ over filtrated solvent. (b). The t-TON over MOF-253- $\operatorname{Re}(\mathrm{CO})_{3} \mathrm{Cl}(\square)$, and $\operatorname{Re}(\mathrm{dcbpy})(\mathrm{CO})_{3} \mathrm{Cl}(\triangle)$.

Fig. 3 XRD patterns for $\mathrm{MOF}-253-\mathrm{Re}(\mathrm{CO})_{3} \mathrm{Cl}$ after (i) and before (ii) the photocatalytic reaction.

Fig. 4 TON comparsion between MOF-253- $\mathrm{Re}(\mathrm{CO})_{3} \mathrm{Cl}$ and sensitized-MOF-253-Re $(\mathrm{CO})_{3} \mathrm{Cl}$ after $4 \mathrm{~h}$ irradiation.

\section{Captions for Schemes}

Scheme 1 General mechanism for photocatalytic $\mathrm{CO}_{2}$ reduction over $[\operatorname{Re}(\mathrm{N}$, $\left.\left.\mathrm{N}^{\prime}\right)(\mathrm{CO})_{3} \mathrm{X}\right]$.

Scheme 2 Proposed mechanism for photocatalytic $\mathrm{CO}_{2}$ reduction over the as-prepared MOF-253- $\operatorname{Re}(\mathrm{CO})_{3} \mathrm{Cl}$ under visible light.

\section{Captions for Tables}

Table 1 TON for photocatalytic $\mathrm{CO}_{2}$ reduction with as-obtained samples under variety conditions. 
Fig. 1
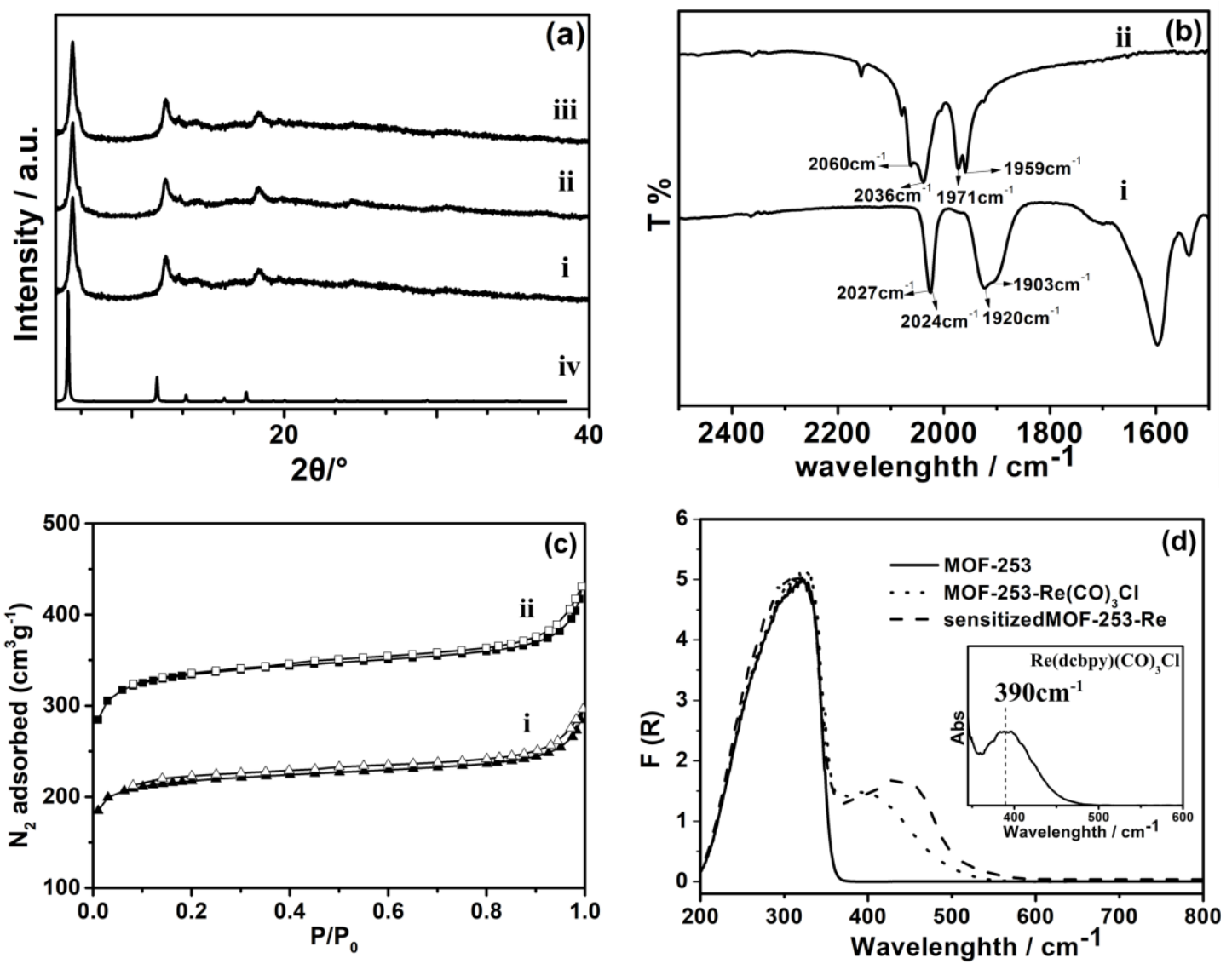
Fig. 2
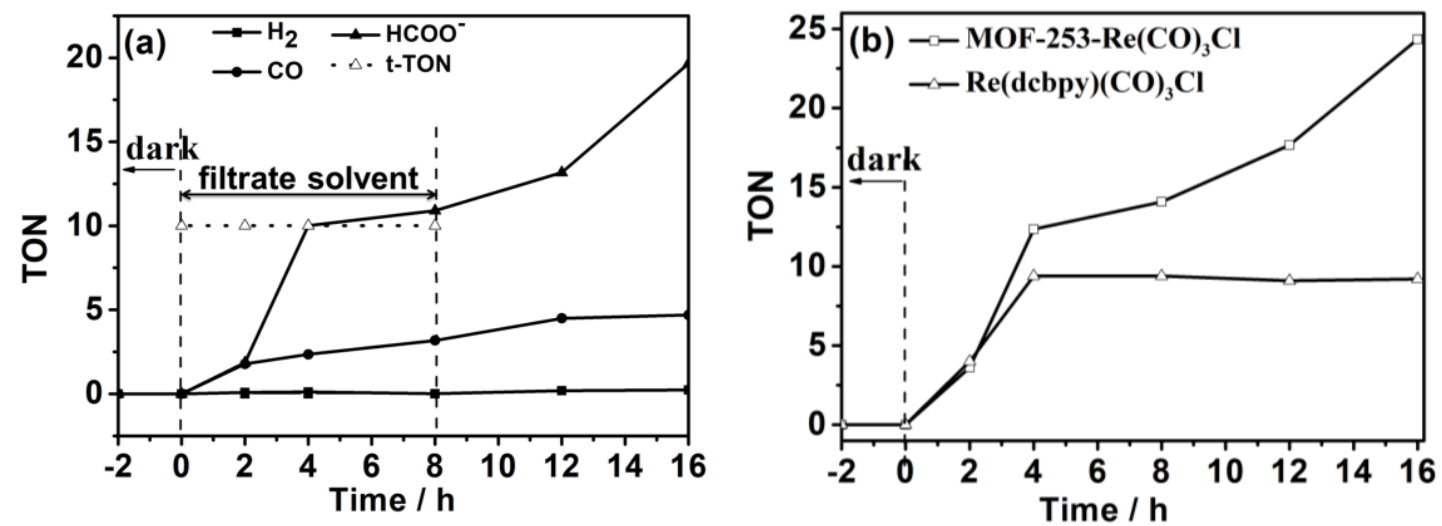
Fig. 3

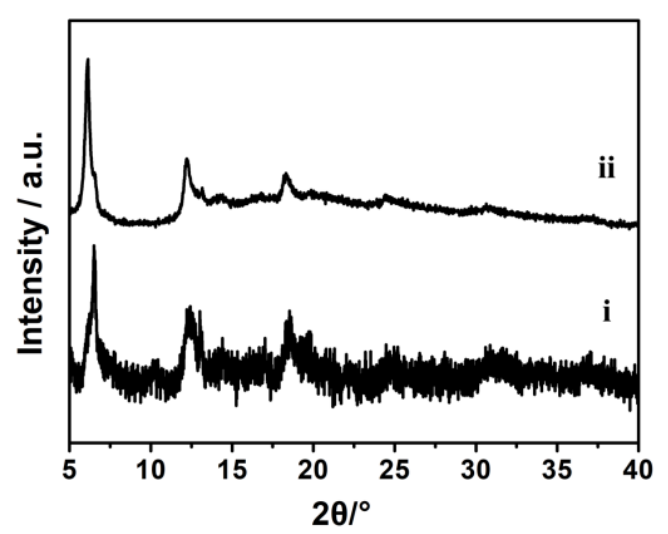


Fig. 4

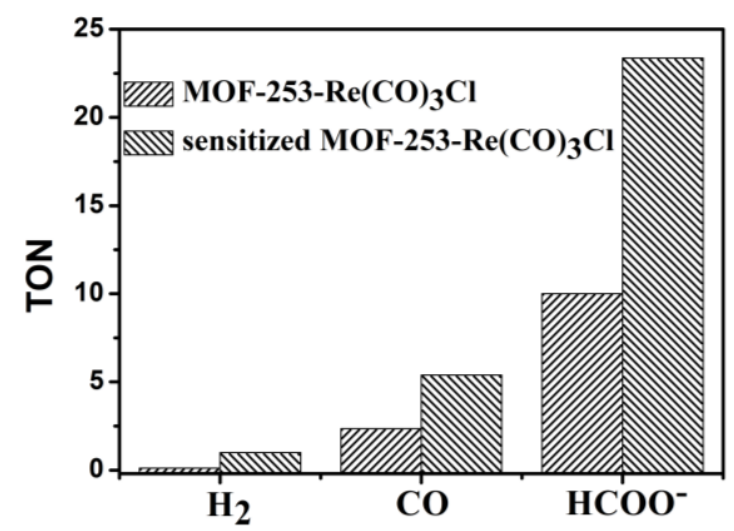




\section{Scheme 1}

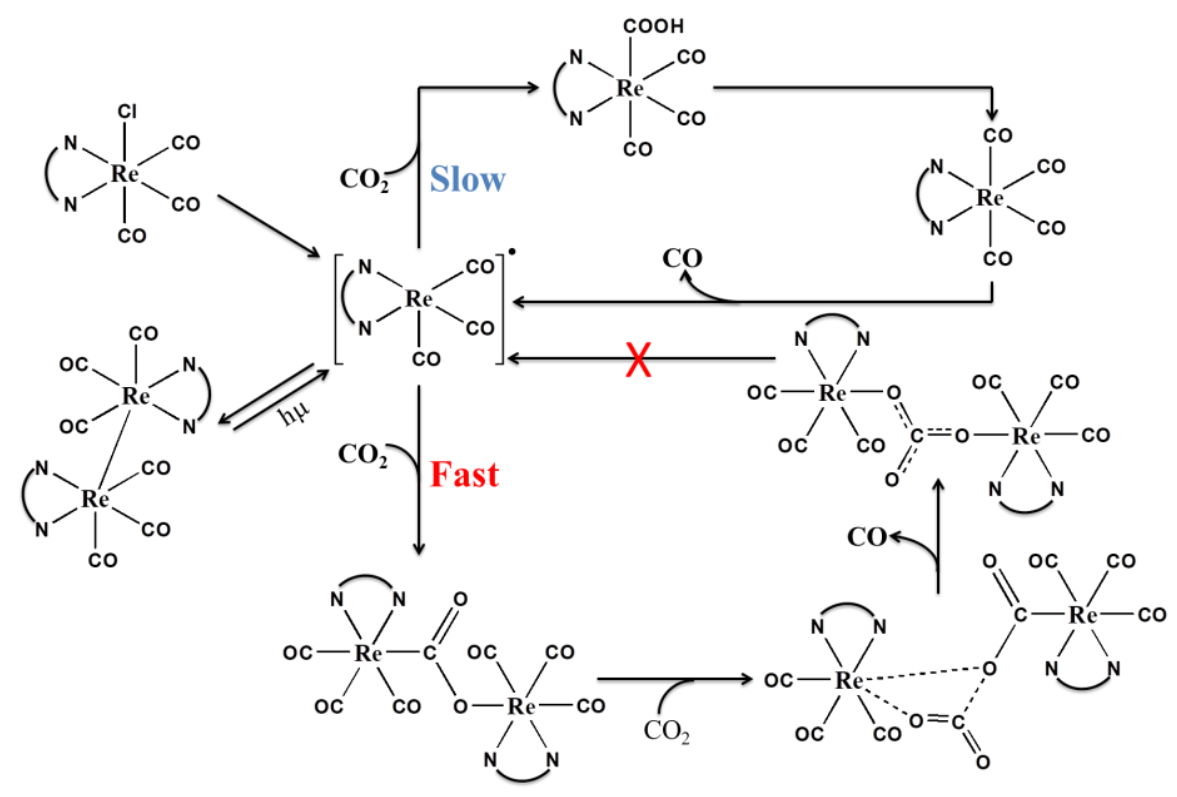


Scheme 2

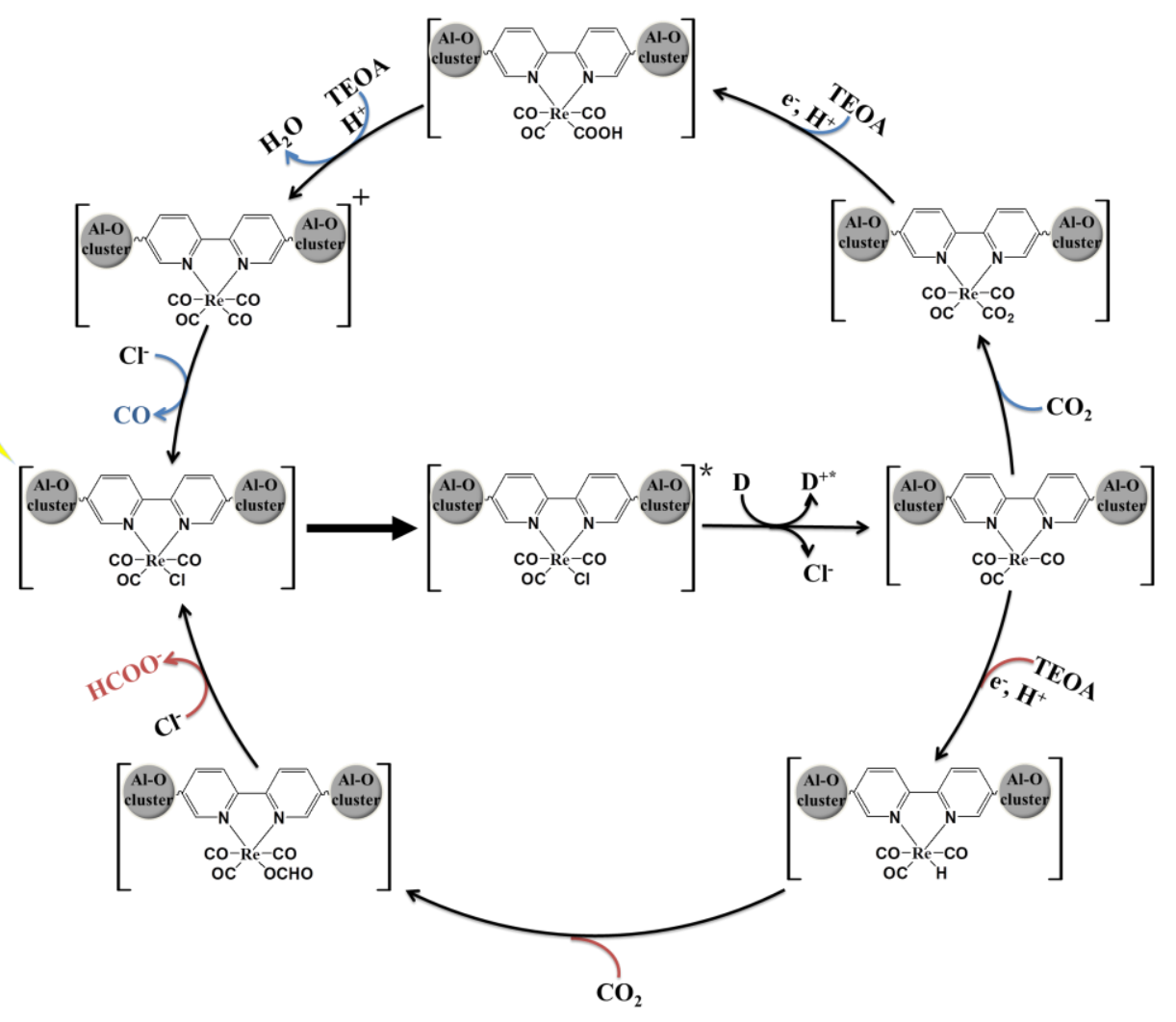


Table 1

\begin{tabular}{|c|c|c|c|c|c|c|c|}
\hline \multirow[b]{2}{*}{$\begin{array}{c}\text { Entr } \\
\mathrm{y}\end{array}$} & \multirow[b]{2}{*}{ Cat. } & \multirow[b]{2}{*}{ Solvent } & \multirow[b]{2}{*}{$\begin{array}{l}\text { Sacrificial } \\
\text { agent }\end{array}$} & \multicolumn{4}{|c|}{ TON(Products) ${ }^{\mathrm{a}}$} \\
\hline & & & & $\mathrm{H}_{2}$ & $\mathrm{CO}$ & $\mathrm{HCOO}^{-}$ & $\begin{array}{c}\mathrm{CO}+\mathrm{HCOO} \\
-\end{array}$ \\
\hline 1 & $\begin{array}{c}\mathrm{MOF}-253-\operatorname{Re}(\mathrm{CO})_{3} \mathrm{C} \\
1\end{array}$ & $\mathrm{DMF} / \mathrm{H}_{2} \mathrm{O}$ & TEOA & 0.1 & 2.4 & 10.0 & 12.4 \\
\hline 2 & MOF-253 & $\mathrm{DMF} / \mathrm{H}_{2} \mathrm{O}$ & TEOA & 0.03 & 0.01 & 0 & 0.01 \\
\hline $3^{b}$ & $\begin{array}{c}\mathrm{MOF}-253-\mathrm{Re}(\mathrm{CO}){ }_{3} \mathrm{C} \\
1\end{array}$ & $\mathrm{DMF} / \mathrm{H}_{2} \mathrm{O}$ & TEOA & 0 & 0 & 0 & 0 \\
\hline $4^{c}$ & $\begin{array}{c}\mathrm{MOF}-253-\operatorname{Re}(\mathrm{CO}){ }_{3} \mathrm{C} \\
1\end{array}$ & $\mathrm{DMF} / \mathrm{H}_{2} \mathrm{O}$ & TEOA & 0.23 & 0 & 0 & 0 \\
\hline 5 & $\begin{array}{c}\mathrm{MOF}-253-\operatorname{Re}(\mathrm{CO}){ }_{3} \mathrm{C} \\
1\end{array}$ & $\mathrm{THF} / \mathrm{H}_{2} \mathrm{O}$ & TEOA & 0.1 & 0.6 & 5.2 & 5.8 \\
\hline 6 & $\begin{array}{c}\mathrm{MOF}-253-\operatorname{Re}(\mathrm{CO}){ }_{3} \mathrm{C} \\
1\end{array}$ & $\mathrm{DMF} / \mathrm{H}_{2} \mathrm{O}$ & TEA & 0.4 & 0.8 & 0.8 & 1.6 \\
\hline 7 & $\begin{array}{c}\mathrm{MOF}-253-\operatorname{Re}(\mathrm{CO}){ }_{3} \mathrm{C} \\
1\end{array}$ & $\mathrm{DMF} / \mathrm{H}_{2} \mathrm{O}$ & - & 0 & 0 & 0 & 0 \\
\hline $8^{d}$ & $\mathrm{Re}(\mathrm{dcbpy})(\mathrm{CO})_{3} \mathrm{Cl}$ & $\mathrm{DMF} / \mathrm{H}_{2} \mathrm{O}$ & TEOA & 0.02 & 9.4 & 0 & 9.4 \\
\hline 9 & $\begin{array}{c}\text { Sensitized- } \\
\text { MOF-253-Re(CO) }{ }_{3} \mathrm{C} \\
1\end{array}$ & $\mathrm{DMF} / \mathrm{H}_{2} \mathrm{O}$ & TEOA & 1.0 & 5.4 & 23.4 & 28.8 \\
\hline 10 & MOF-253-Ru & $\mathrm{DMF} / \mathrm{H}_{2} \mathrm{O}$ & TEOA & 0.02 & 0.08 & 0.6 & 0.68 \\
\hline $11^{\mathrm{e}}$ & {$\left[\mathrm{Ru}(\mathrm{bpy})_{2} \mathrm{Cl}_{2}\right]_{2}$} & $\mathrm{DMF} / \mathrm{H}_{2} \mathrm{O}$ & TEOA & 0.1 & 0.02 & 0.1 & 0.1 \\
\hline
\end{tabular}

Conditions: catalyst $(5 \mathrm{mg})$, solvent (DMF: $\left.\mathrm{H}_{2} \mathrm{O}=25: 1,3.4 \mathrm{~mL}\right)$, sacrificial agent $(0.6 \mathrm{ml})$, visible light irradiation $\left(400 \mathrm{~nm} \leqslant \lambda \leqslant 800 \mathrm{~nm}\right.$ ), under $\mathrm{CO}_{2}$ atmosphere. Reaction time (4h). ${ }^{\mathrm{a}}$ The evolution of gaseous products and liquid products was calculated by GC and IC respective, TON is defined as mole of the evolved $\mathrm{H}_{2} \mathrm{CO}$ and $\mathrm{HCOO}^{-}$over per amount of Rhenium, ${ }^{\mathrm{b}}$ no light, ${ }^{\mathrm{c}}$ under $\mathrm{N}_{2}$ atmosphere, ${ }^{\mathrm{d}}$ catalyst $(2 \mathrm{mg}),{ }^{\mathrm{e}}$ catalyst $(2 \mathrm{mg})$, TON calculated by the mole of ruthenium in catalyst. 